\title{
INTRODUCTION \\ The Future Role OF HeAlth LAW ANd MedicARe: The Holy Grail of ACCESS, Quality, AND Sustainability
}

\author{
LORIAN HARDCASTle, ${ }^{*}$ COLlEEN M. FlOOD ${ }^{* *}$ \\ AND UBAKA OGBOGU***
}

How is the future performance of our health care system tied to the future of health law? Health policy scholars frequently enumerate three key health system goals: improved access to health care services, appropriate quality of care, and ensuring the sustainability of public medicare through cost control. This triumvirate is sometimes referred to as the "iron triangle" because its three goals can be in tension with one another; such as when efforts aimed at improving access or making health care safer result in increased costs. Law is deeply implicated in this balancing act. For example, the recognition of a legal "right" to health care may improve access but create sustainability challenges for public plans. Similarly, while stringent regulations may improve the safety of pharmaceuticals, this comes with increased regulatory costs and may delay patient access to life-saving medication.

To help provide a greater understanding of the role of law vis-à-vis the health care system, the University of Ottawa Centre for Health Law, Policy and Ethics brought together leading health law experts from across Canada and abroad, including several colleagues from the University of Alberta's Faculty of Law, for the seventh National Health Law Conference on the theme "The Future of Health Law." Several of the articles presented at this November 2015 conference appear in this publication, along with a forthcoming issue of the McGill Journal of Law and Health and recent issues of the Dalhousie Law Journal ${ }^{2}$ and the Ottawa Law Review. ${ }^{3}$ Although these articles explore a diverse array of topics - reproduction, mental health, patient safety, Aboriginal health, end-of-life care, and migrant health - each one illuminates how the future of health law impacts the "iron triangle."

The first four articles in this issue examine the difficulties vulnerable populations face in accessing health care services. For example, indigenous Canadians face the highest mortality and morbidity rates in the country, and many communities struggle with access to necessities such as clean water, housing, and lack basic health care services. ${ }^{4}$ In their contributions to this special issue, Constance MacIntosh and Yvonne Boyer explore the role of law in responding to the health needs of indigenous Canadians. Boyer's article focuses on the unique health concerns of First Nations, Metis, and Inuit women. ${ }^{5}$ She argues that their

\footnotetext{
Associate Director, Centre for Health Law, Policy and Ethics, and Assistant Professor, Faculty of Law, University of Ottawa.

*** Director, Centre for Health Law, Policy and Ethics and Professor, Faculty of Law, University of Ottawa.

*** Assistant Professor, Faculty of Law and Faculty of Pharmacy and Pharmaceutical Sciences, University of Alberta.

William L Kissick, Medicine’s Dilemmas: Infinite Needs Versus Finite Resources (New Haven: Yale University Press, 1994).

(2016) 39:2 Dal LJ.

(2016) 47:2 Ottawa L Rev.

National Collaborating Centre for Aboriginal Health, The State of Knowledge of Aboriginal Health: A Review of Aboriginal Public Health in Canada (Prince George: NCCAH, 2013), online: <www.nccahccnsa.ca/Publications/Lists/Publications/Attachments/52/SOK_report_EN_web.pdf $>$.

$5 \quad$ Yvonne Boyer, "First Nations, Metis, and Inuit Women's Health: A Rights-Based Approach" (2017) 54:3 Alta L Rev 611.
} 
health status could be improved through a human rights-based approach that addresses constitutionally protected rights through the lenses of an indigenous appreciation of rights and of women's substantive equality. In her article, MacIntosh addresses the issue of indigenous mental health ${ }^{6}$ - a problem whose urgency was brought to national attention in 2016, with reports that 101 individuals from an Aboriginal community of 2,000 residents had attempted suicide in an 8 month period. ${ }^{7}$ MacIntosh looks past the point of creating legal rights to the realization of those rights, arguing that if governments undertook to meaningfully fulfill their present obligations, this would produce considerable gains in the mental health of indigenous Canadians.

In their respective articles, Y.Y. Brandon Chen and Ravi Malhotra explore access to health services for another vulnerable group - migrants. Chen argues that immigration and health care policies have created a migrant underclass who, because they are perceived as being temporary or illegal, are not viewed as deserving publicly-funded care or are deprived of meaningful access to services. ${ }^{8}$ One of the arguments against funding health care for refugees is the cost of such services, which has been estimated at $\$ 84$ million per year. ${ }^{9}$ However, increased costs may be justified in light of the fact that cuts to the federal program supporting migrants will cost the system more overall, and untreated illness will put the public at risk. ${ }^{10}$ In his article, Malhotra reflects on this tension between cost and access for a particularly vulnerable group of immigrants: those living with disabilities. ${ }^{11} \mathrm{He}$ argues that "people with disabilities have been historically regarded as undesirable immigrants because they have been perceived as a financial burden to the state" and he critiques the statutory and regulatory mechanisms used to bar people with disabilities from immigrating to Canada. ${ }^{12}$ In this regard, while controlling costs and sustainability is a valid concern for any health care system, it cannot be achieved disproportionately on the backs of the most vulnerable, even in the immigration context.

Although women have made significant gains in access to reproductive services, for example through the decriminalization of abortion, many cost-related barriers still exist, such as the financial barriers to contraceptives and abortions, or the limited public financing of reproductive technologies such as in vitro fertilization. There are also significant concerns with the quality of reproductive services due, for example, to the limited information we have on assisted reproductive practices, and the gap in oversight following the dismantling of Assisted Human Reproduction Canada, the federal regulatory agency that was charged with

6 Constance MacIntosh, "Indigenous Health: Imagining a Future Where Action Follows Obligations and Promises" (2017) 54:3 Alta L Rev 589.

$7 \quad$ Kady O'Malley, “End the Culture of Deniability': Attawapiskat Youth Suicide Crisis Subject of Emergency House Debate" Ottawa Citizen (12 April 2016), online: <ottawacitizen.com/news/politics/ attawapiskat-youth-suicide-crisis-subject-of-emergency-house-debate $>$.

8 YY Brandon Chen, "The Future of Precarious-Status Migrants' Right to Health Care in Canada" (2017) 54:3 Alta L Rev 649.

$9 \quad$ André Picard, "Why Cutting Care for Asylum-Seekers Makes No Sense" The Globe and Mail (14 May 2012), online: <www.theglobeandmail.com/life/health-and-fitness/why-cutting-health-care-for-asylumseekers-makes-no-sense/article4178642/>.

10 Letter from Ontario Minister of Health and Long-Term Care Deb Matthews to Federal Minister of Health Leona Aglukkaq and Federal Minister of Citizenship and Immigration Jason Kenney (27 June 2012), online: Ontario Ministry of Health and Long-Term Care <www.health.gov.on.ca/en/news/ bulletin/2012/docs/hb_20120629_2.pdf>.

11 Ravi Malhotra, "The Impact of the Convention on the Rights of Persons with Disabilities on Canadian Jurisprudence: The Case of Leobrera v. Canada" (2017) 54:3 Alta L Rev 637. Ibid. 
implementing the Assisted Human Reproduction Act. ${ }^{13}$ In their contributions to this issue, Erin Nelson ${ }^{14}$ and Joanna Erdman ${ }^{15}$ address some of the persistent access issues that women face. Erdman examines the legal and policy developments that unfolded in Prince Edward Island after the government responded to $R$. $v$. Morgentaler ${ }^{16}$ with a legislative resolution opposing the provision of abortion services. She explores how the cumulative forces of political activism on the part of a local interest group, a constitutional challenge to the province's abortion policy, and the compelling stories of women affected by the abortion policy, led to a 2016 decision to open a hospital-based clinic offering reproductive services. In her article, Nelson similarly highlights concerns with access to contraceptives and abortion in the wake of Morgentaler, and in particular, the judicial charge to governments to develop a comprehensive policy strategy on reproductive care. While acknowledging the financial implications, such as the costs associated with provincial governments offering funding for contraceptives, she argues that women's equality and autonomy are dependent upon access to reproductive services.

Two contributions byVanessa Gruben, one co-authored with Angela Cameron, further address policy issues associated with access to reproductive technologies. In one article, both authors discuss the problem faced by children conceived through assisted reproduction, who may lack access to basic familial health history. ${ }^{17}$ This has clear implications for the ability of those children to receive appropriate health services, given that they may be unaware of genetic health conditions that call for early screening. Gruben and Cameron highlight the plethora of legal issues arising in the context of donor anonymity, including the federal and provincial division of powers, the impact of prohibitions on the commercialization of reproductive materials on gamete supply, the failure to enact family laws to protect the parental status of intended parents, and constitutional arguments regarding a right to know one's genetic origins. In a second article, Vanessa Gruben addresses the issue of egg freezing. ${ }^{18}$ As with Nelson, she links access to reproductive services with autonomy, but argues that regulation is required for this technology to truly promote autonomy. Gruben's article explores all three dimensions of the health policy triad, including the costs associated with egg freezing, the lack of information on quality and safety, and the need for access to such health services as fertility education and reproductive counselling.

Canada's ability to balance access, quality, and sustainability will be tested even further as its population ages. Policy challenges include how to pay for the services needed by aging baby boomers (such as home care and long-term care), how to manage increased demands for timely access to elective surgery, the allocation of limited long-term care spaces (and long wait times), and quality concerns, such as gaps in oversight of nursing homes. Into this complex policy domain, Canada must now factor in the implications of the Supreme Court

SC 2004, c 2; Francoise Baylis, "The Demise of Assisted Human Reproduction Canada" (2012) 34:6 J Obstetrics Gynecology Can 511.

Erin Nelson, "Autonomy, Equality, and Access to Sexual and Reproductive Health Care" (2017) 54:3 Alta L Rev 707.

Joanna N Erdman, "A Constitutional Future for Abortion Rights in Canada" (2017) 54:3 Alta L Rev 727.

[1988] 1 SCR 30 [Morgentaler].

Vanessa Gruben \& Angela Cameron, "Donor Anonymity in Canada: Assessing the Obstacles to Openness and Considering a Way Forward: (2017) 54:3 Alta L Rev 665.

Vanessa Gruben, "Freezing as Freedom? A Regulatory Approach to Elective Egg Freezing and Women's Reproductive Autonomy" (2017) 54:3 Alta L Rev 753. 
of Canada's decision in Carter v. Canada (Attorney General), which decriminalizes medical aid in dying. ${ }^{19}$ The Carter case raises its own issues of cost, access, and quality of care, including access issues posed by provider conscientious objections, concerns that poor quality palliative care in Canada may prompt patients to seek assisted suicide prematurely, and the financial costs associated with developing and implementing regulatory schemes designed to address medical aid in dying and other end-of-life care. The articles by Jocelyn Downie, Lindy Willmott, and Ben P. White ${ }^{20}$ and by Juliet Guichon, Farah Mohamed, Kim Clarke, and Ian Mitchell ${ }^{21}$ examine a number of the key challenges that lie in our future. In the wake of Carter, debates persist around which groups should be excluded from accessing medical aid in dying. Guichon and colleagues address one such group - mature minors. These patients, who possess the capacity to make medical decisions, are nonetheless often denied the right to refuse lifesaving care, which may extend to the context of assisted dying. Through the lens of autonomy and beneficence, the authors consider the Canadian assisted dying framework, situations in which minors might seek assistance dying, the legal principles governing mature minors more generally, and other jurisdictions that grant access to mature minors. In their contribution, Downie and colleagues argue that policymakers must not only allocate resources to assisted dying but also focus their attention upon another pressing issue: the unilateral withholding and withdrawal of life-sustaining treatment. Specifically, what should happen when the health care team believes that treatment is futile, while the family wishes to continue life-sustaining care, often at great public expense? The authors argue for an approach to law reform that more closely aligns with the fundamental values it purports to serve and which results in better care for the living and the dying.

With respect to the quality of health care, there are serious concerns with the safety of hospitals, especially given that tens of thousands of avoidable injuries occur every year in Canadian hospitals. ${ }^{22}$ The articles by Tom Archibald and Lorian Hardcastle address this pressing quality of care concern. Archibald engages with the tension between cost containment and quality, arguing that the former has generally dominated health policymaking. ${ }^{23} \mathrm{He}$ explores this problem in the context of human resource issues, such as the impact of nursing staffing levels on patient safety and the costs associated with investing in health care workers. Hardcastle's article similarly explores how systems-level reforms affect patient safety. ${ }^{24}$ She argues that refocusing liability from providers to hospitals would better align legal accountability with the ability to prevent injuries. She also explores a variety of legislative reforms to hospital governance, with a view to catalyzing the adoption of governance practices aimed at improving patient safety. Finally, she argues for a rethinking of the legal relationship between hospitals and physicians, which could make it easier for hospitals to respond to concerns with quality of care.

2015 SCC 5, [2015] 1 SCR 332 [Carter].

Jocelyn Downie, Lindy Willmott \& Ben P White, "Next Up: A Proposal for Values-Based Law Reform on Unilateral Withholding and Withdrawal of Potentially Life-Sustaining Treatment" (2017) 54:3 Alta L Rev 803.

Juliet Guichon et al, "Autonomy and Beneficence in Assisted Dying in Canada: The Eligibility of Mature Minors" (2017) 54:3 Alta L Rev 775. This article was submitted directly to the Alberta Law Review and was not presented at the National Health Law Conference.

G Ross Baker et al, "The Canadian Adverse Events Study: The Incidence of Adverse Events Among Hospital Patients in Canada" 170:11 CMAJ 1678.

Tom Archibald, "Efficiency and the Pursuit of Patient Safety" (2017) 54:3 Alta L Rev 681.

Lorian Hardcastle, "Legal Mechanisms to Improve Quality of Care in Hospitals" (2017) 54:3 Alta L Rev 681. 
The special issue is bookended by Jennifer A. Chandler's innovative contribution to the conceptual and legal analysis of the complex policy issues associated with mental illnesses. ${ }^{25}$ Although we typically conceptualize mental illness as a medical issue, Chandler challenges us to reconsider our current understanding of mental illness. She argues that the biological theory of mental illness has given us a better understanding of the causal contributions to mental illness, which may improve the quality of mental health services by enabling researchers to design better preventive strategies and more effective treatments. The optimism surrounding advances in treatment must, of course, be tempered by concerns with access to and funding for mental health services. Chandler raises further challenges to this model by arguing that biological psychiatry encourages certain patterns of thought that have social, political, and legal consequences.

Although the "Future of Health Law" theme is forward-looking, this conference and these special journal articles were also an opportunity to reflect on the evolution of the field of health law and to celebrate the close-knit health law community. The conference marked the finale of the 13 year Canadian Institutes of Health Research (CIHR) Training Program in Health Law, Ethics and Policy. This program provided funding for 134 students pursuing masters and doctoral degrees in health law across Canada. Alumni have gone on to influential positions in private practice, health organizations, federal and provincial ministries of health, and academia. Several contributors to this issue are either alumni of the training program (Tom Archibald, Y.Y. Chen, Lorian Hardcastle, and Ubaka Ogbogu), mentored students in the program (Jennifer A. Chandler, Joanna Erdman, and Erin Nelson), or were program founders (Jocelyn Downie and Colleen M. Flood). It is our hope that the program will have an enduring legacy, with graduates continuing to generate the evidence necessary to aid policymakers in grappling with the tensions arising between the goals of access, quality of care, and cost containment. 
